\title{
Modeling and Simulation of Pore Formation in a Bainitic Steel During Creep
}

\author{
FELIX MEIXNER, MOHAMMAD REZA AHMADI, and CHRISTOF SOMMITSCH
}

\begin{abstract}
In the field of power engineering, where materials are subjected to high pressures at elevated temperatures for many decades, creep-resistant steels are put to work. Their service life is still, however, finite, as the many changes in their microstructure can merely be mitigated and not avoided. Creep cavitation is one of those changes and, in many cases, ultimately causes failure by rupture. In this work, a model is proposed to simulate the nucleation and growth of cavities during creep. This exclusively physics-based model uses modified forms of Classical Nucleation Theory and the Onsager Extremum Principle in a newly developed Kampmann-Wagner framework. The model is validated on P23 steel which underwent creep rupture experiments at $600{ }^{\circ} \mathrm{C}$ and stresses of 50, 70, 80, 90 and $100 \mathrm{MPa}$ for creep times up to 46000 hours. The model predicts qualitatively the shape and prevalence of cavities at different sites in the microstructure, and quantitatively the number density, size of cavities and their phase fraction contributing to a reduction in density. Finally, we find good agreement between the simulation and the experimental results especially at low stresses and longer creep times.
\end{abstract}

https://doi.org/10.1007/s11661-021-06569-y

(C) The Author(s) 2022

\section{INTRODUCTION}

As the need for more efficient and cleaner energy production increases, advanced thermal power plants will need to operate at ever higher temperatures and pressures. Materials are being developed to fulfill those requirements. ${ }^{[1]}$ However, they are still susceptible to creep damage by cavitation of voids, growth and interlinkage of these cavities and then finally rupture and failure. ${ }^{[2,3]}$ The high homologous (relative to the melting point) temperatures of 0.3 to 0.5 promote the nucleation, growth, and coalescence of these cavities due to the increased thermal energy of the atoms and greater mobility of vacancies. Economic considerations and technical requirements also complicate material selection and are leading to the predominant application of low alloyed steels in piping and boiler systems.

Ashby ${ }^{[4]}$ has outlined, in his eponymous Ashby maps, the many different mechanisms leading to deformation and destruction of the microstructure of these materials put under these loads, which is known as creep. The focus of this study is on diffusional creep, which is a result of the diffusion of vacancies at lower stresses and

FELIX MEIXNER, MOHAMMAD REZA AHMADI, and CHRISTOF SOMMITSCH are with the Institute of Materials Science, Joining and Forming, Graz University of Technology, Kopernikusgasse 24/I, 8010 Graz, Austria. Contact e-mail: felix.meixner@tugraz.at

Manuscript submitted September 22, 2021; accepted: December 2, 2021. Article published online January 7, 2022 high temperatures. This is the most important case for creep-resistant metals used in sub-critical power generation facilities approaching service lifetimes of 30 years or more. Dislocation creep leads to quicker rupture and is more sensitive to the creep stress. The development of ultra-supercritical (USC) and advanced ultra-supercritical (A-USC) power plants along with their operation at ever higher temperatures and pressures will lead to a greater importance of dislocation creep. ${ }^{[5]}$

We see great value in developing a physics-based model for the nucleation and growth of cavities. Previous efforts ${ }^{[6,7]}$ are mostly based on empirical or semi empirical models, requiring prior knowledge of the strain rate $\dot{\varepsilon}$ to estimate cavity nucleation. However, it is still not well established by what mechanism cavities nucleate. ${ }^{[8]}$

$\mathrm{He}$ and Sandström ${ }^{[9]}$ have shown that grain boundary sliding could be one such mechanism, demonstrating the expected linear relationship between cavity nucleation rate and strain rate. This relationship has long since been proposed by Dyson ${ }^{[10]}$ and is still in wide use today. ${ }^{[11]}$ The model used in this work is developed from previous efforts, ${ }^{[12]}$ is based on Classical Nucleation Theory (CNT) and uses Helmholtz free energies as the driving force, as proposed by Raj and Ashby. ${ }^{[13]}$ As such, this model considers nucleation events to be a combination of kinetic processes and thermal fluctuations. During creep at high temperatures nanosized cavities are continuously nucleated and grow, as do previously existing cavities. The novelty in this application lies in the introduction of a Kampmann-Wagner 
framework to model the nucleation and growth of multiple different cavities of different ages and sizes.

Intergranular failure is caused by the coalescence of cavities along the grain boundaries and characterizes the beginning of tertiary creep. ${ }^{[14]}$ The proposed model and experimental results as well as previous studies ${ }^{[15]}$ have identified cavities at grain boundaries to appear more frequently and grow more quickly than those elsewhere in the microstructure, therefore playing a critical role in material creep life.

The simulation results of the suggested model will be multidimensionally validated against density measurements and microstructural observations of cavity size and number density in crept samples of P23 steel, which is designed for use in power plants. ${ }^{[16]}$

These simulation results can be applied in Eq. [1] by Siefert and Parker ${ }^{[17]}$ to estimate creep life based on the cavity number density,

$$
\frac{t}{t_{\mathrm{r}}}=1-\left(1-\frac{N_{\mathrm{s}}}{N_{\mathrm{sf}}}\right)^{\lambda}
$$

where $t / t_{\mathrm{r}}$ represents the relative creep life to fracture and, $N_{\mathrm{s}} / N_{\mathrm{sf}}$ is the number of cavities relative to those present at rupture. $\lambda$ is a constant and varies between 2 and 3 for brittle and ductile materials, respectively.

\section{METHODS}

\section{A. Creep Testing}

Creep-rupture tests were carried out on 5 samples of P23 steel, which is a weaker and cheaper alternative to P91 and other 9 pct-Chromium steels and is used in power plants in membrane water-walls, superheater tubes and steam drums. ${ }^{[18]}$ It is an evolution of T22 Steel, with modifications to its chemical composition including the addition of Tungsten (1.6 pct) and reduction of the Carbon and Molybdenum content. Nitrogen, Niobium, Boron and Vanadium are also added in trace amounts to stabilize the microstructure. The analyzed chemical composition is given in Table I.

Heat treatment was carried out in accordance with ASTM A 213 Code Case 2199 on forged samples after water quenching. The specified austenitizing at $1060{ }^{\circ} \mathrm{C}$ and cooling in air, followed by tempering at $760{ }^{\circ} \mathrm{C}$ for 2 hours resulted in a bainitic microstructure. ${ }^{[19,20]}$

From this material, standard creep test samples were machined, similar to DIN 50125 B specifications, with M16 threads for mounting, a gauge length between 35 and $50 \mathrm{~mm}$ and varying gauge diameters to produce the corresponding stresses in the samples which are shown in Table II. The samples were loaded until failure in a furnace (built by Mohr \& Federhaff AG) and held at a constant temperature $\left(600{ }^{\circ} \mathrm{C}\right)$. The load was applied by system of levers and a weight and a motor driven leadscrew takes up the samples' strain to keep the lever horizontal. Table II shows the time to rupture of each sample and the total strain at rupture. The samples only displayed slight necking at failure ( $>85$ pct of original gauge diameter at rupture).

\section{B. Density Measurements}

The creep samples were sectioned longitudinally and a short segment $(\sim 20 \mathrm{~mm})$ between the fracture surface and the head was cut out. All surfaces were stripped of rust and corrosion. Five density measurements of each sample fragment were made in ethanol using a Radwag PS210.X2 Precision balance and density determination kit by Archimedes' Principle. These measurements were averaged and used to determine the reduction in density due to cavitation for each sample. From this, the volume fraction occupied by cavities was calculated.

\section{Scanning Electron Microscopy}

To investigate the microstructure, the opposite sides of the longitudinally cut samples were embedded in Struers Polyfast and ground and polished, at first with Silicon carbide paper, then with diamond polishing paste $(9 \mu, 1 \mu)$ and finally, with Struers' OP-S suspension at low forces $(15,10$ and $5 \mathrm{~N}$ per sample) and for longer periods (each step took 20 minutes). A Tescan Mira3 FEG Scanning Electron Microscope (SEM) was used with its in-beam secondary electron detector at excitation voltages between 1 and $10 \mathrm{kV}$. The inspected area was several (20 to 30$) \mathrm{mm}$ away from the fracture surface. Each sample was scanned by the operator (focusing mostly on grain boundaries) and images of suitable clusters of cavities were acquired.

\section{Image and Data Processing}

The Image processing toolbox of MATLAB R2020a was used to detect the radii of cavities. Manually defined regions of interest (ROIs) were selected using a custom uicontrol element and then used to limit the search for circular features using MATLAB's built-in imfindcircles function, which is based on the Hough transform. The circle with a radius between ten and fifty percent of the ROI's width with the highest strength was taken to represent the cavity radius. Statistical analyses were performed in MATLAB and Microsoft Excel.

\section{MODEL DEVELOPMENT}

To simulate the nucleation and growth of cavities, CNT will be used which is based on the work done by Volmer and Weber, ${ }^{[21]}$ Becker and Döring, ${ }^{[22]}$ Frenkel $^{[23]}$ and Zeldovich. ${ }^{[24]} \mathrm{CNT}$ has achieved great success over the past 80 years modeling crystallization, ${ }^{[25]}$ phase transformations, ${ }^{[26]}$ condensation $^{[27]}$ and precipitate nucleation in different aluminum alloys, superalloys and steels. ${ }^{[28]}$

The subsequent growth of these nanoscopic nuclei into micro and macroscopic cavities is simulated using a model proposed by Svoboda et al., ${ }^{[29]}$ which is used in the materials calculator software Matcalc dealing with precipitates and phases. ${ }^{[30]}$ 
Table I. Chemical Composition of the P23 Steel Used in This Study

\begin{tabular}{lccccccccccccc}
\hline Elements & $\mathrm{C}$ & $\mathrm{Cr}$ & $\mathrm{Mo}$ & $\mathrm{W}$ & $\mathrm{N}$ & $\mathrm{Nb}$ & $\mathrm{B}$ & $\mathrm{V}$ & $\mathrm{S}$ & $\mathrm{Si}$ & $\mathrm{Mn}$ & $\mathrm{P}$ & $\mathrm{Al}$ \\
\hline Wt Pct & 0.07 & 2.08 & 0.08 & 1.65 & 0.011 & 0.03 & 0.002 & 0.22 & 0.004 & 0.28 & 0.54 & 0.008 & 0.018 \\
\hline
\end{tabular}

Table II. Creep Conditions and Times to Rupture of the Samples Applied in This Research

\begin{tabular}{lccccc}
\hline Sample ID & Temperature $\left({ }^{\circ} \mathrm{C}\right)$ & Stress $(\mathrm{MPa})$ & Gauge Diameter $(\mathrm{mm})$ & Time to Rupture (h) & Rupture Strain $(1)$ \\
\hline S10 & 600 & 100 & 7.07 & 4873 & 0.0412 \\
S11 & 600 & 80 & 7.45 & 8995 & 0.0345 \\
S12 & 600 & 70 & 7.90 & 12,984 & 0.0170 \\
S13 & 600 & 50 & 10.45 & 25,093 & 0.0166 \\
S14 & 600 & & & 46,321 & 0.0266 \\
\hline
\end{tabular}

\section{A. Classical Nucleation Theory}

Classical Nucleation Theory uses a thermodynamic approach to model nucleation kinetics. Considering the change in free energy as the driving force for changes in the microstructure, the nucleation rate is dependent on the free energy of the newly nucleated phase. The fundamental equation is given below:

$$
I=N_{\mathrm{s}} \beta^{*} Z \exp \left(-\frac{\Delta G \text { or } \Delta \mathrm{F}}{R T}\right)
$$

This provides us with an estimate for the number of nucleation events per unit volume per unit time $I$, whereby $N_{\mathrm{s}}$ is the number of sites per unit volume where nucleation could occur, $\beta^{*}$ is the attachment frequency of particles of the new phase to the growing nucleus, $Z$ is the so-called Zeldovich factor, which accounts for the fact that not all nuclei which grow to a stable size will also grow further and the exponential term which gives us the probability of finding a nucleus with the needed Gibbs free energy $\Delta G$ for nucleation of new precipitates in the microstructure as it is described in Reference 28 or the Helmholtz free energy $\Delta F$ for nucleation of cavities as described in References 31 and 32. The exponential term has a decisive role on the nucleation rate. As a nucleus forms, an interface is created between it and the surrounding bulk material, the creation of which increases the total free energy of the system. Nucleation of a new phase or cavity is favorable for the system if it has a lower free energy than the material in which it nucleates. Its effect on the total free energy is directly proportional to the volume of the new phase (in this case, cavity). As an example, the free energy change vs the radius of a cavity in hydrostatic tension under 100 $\mathrm{MPa}$ and a surface energy of $1.6 \mathrm{~J} \mathrm{~m}^{-1}$ is demonstrated in Figure 1.

The free energy change reaches its maximum, $\Delta F^{*}$ at the critical radius $r^{*}$ which is given by:

$$
r^{*}=\frac{2 \gamma_{\mathrm{s}}}{\sigma}
$$

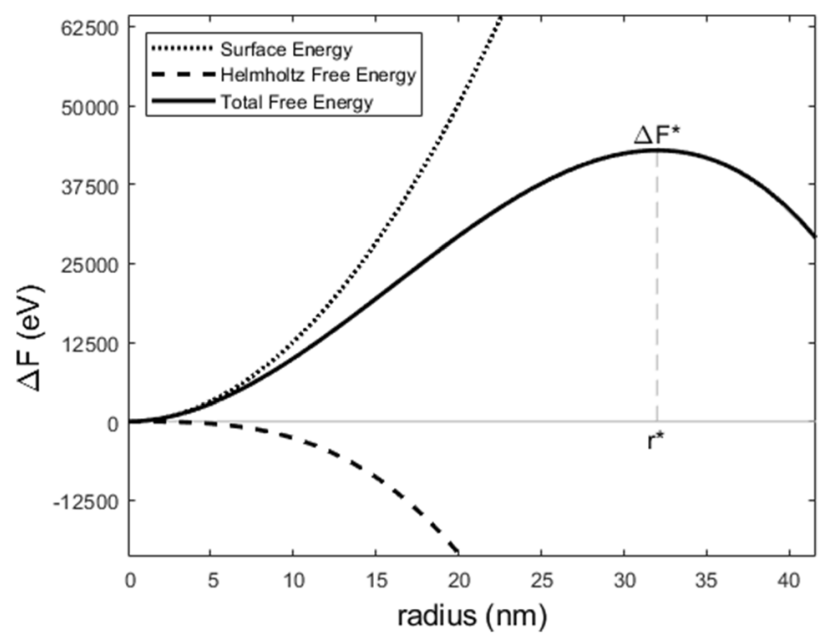

Fig. 1-Free energy change as a function of cavity radius.

where $\gamma_{\mathrm{s}}$ and $\sigma$ represent the surface energy and applied stress, respectively.

\section{B. Nucleation of Cavities}

Early applications of CNT to the nucleation of cavities in metals in creep conditions were done by Raj and Ashby. ${ }^{[13]}$ Other authors have developed this model for the nucleation of cavities over the years. ${ }^{[12,32]}$ This model takes the mechanical stress $\sigma$, which has the unit of force per area or energy per volume and uses it as the driving force of free energy change due to the nucleation of cavities. ${ }^{[33,34]}$ The internal stress (back-stress) attributed to the hindrance of dislocation motion by precipitates does not reduce the driving force in this model.

The interfacial energy is taken to be the free surface energy with some modifications which are described in Reference 35 . The number of possible nucleation sites is equal to the number of atomic sites, in the bulk. As derived in Reference 28 the Zeldovich factor is 


$$
Z=\sqrt{\frac{\Omega^{2} \sigma^{4}}{64 \pi R T \gamma_{m}^{3}}}=\sqrt{\frac{\Delta F^{*}}{3 \pi R T}} \frac{1}{n^{*}}
$$

Cavities that have attained the critical size are still more likely to dissolve than they are to continue growing. This was considered in the Zeldovich factor by its namesake. ${ }^{24}$ The graphical derivation of the Zeldovich factor is shown in Figure 2, whereby the $\mathrm{x}$ axis displays the number of vacancies in the cavity. In this figure, a region is defined by the intersections of a certain amount of energy below the critical free energy $\left(\Delta F^{*}-R T\right)$ with the curve of the total free energy, the rightmost being defined as $n^{*}$. The width of this region is the reciprocal of the Zeldovich factor. Cavities must pass through this region during nucleation while they are still susceptible to dissolution. Any supercritical cavities larger than $n^{*}$ are more than one quantum of energy $(R T)$ away from dissolving and will continue to grow as they reduce the overall free energy.

Another important term introduced in Eq. [5] is the atomic attachment rate $\beta^{*}$, which is defined as,

$$
\beta^{*}=\frac{\sqrt[3]{4 \pi\left(3 \Omega n^{*}\right)^{2}}}{\sqrt[3]{\Omega^{4}}} n_{\mathrm{v}} D_{\mathrm{v}}=\frac{A^{*}}{\sqrt[3]{\Omega^{4}}} n_{\mathrm{v}} D_{\mathrm{v}}
$$

whereby $A^{*}$ is the surface area of a critical cavity, $n_{\mathrm{v}}$ is the concentration of vacancies in the matrix, $D_{\mathrm{v}}$ is the diffusion coefficient of those vacancies and $\Omega$ is the atomic volume. This describes the frequency with which new vacancies attach to the cavity.

\section{Heterogeneous Nucleation}

All the formulas above are derived for spherical cavities forming in the matrix of the material, which is known as homogeneous nucleation. However, as typical for crystalline metals, most of the interesting phenomena occur at the grain boundaries. This leads to what is called heterogeneous nucleation. The shapes of the cavities formed can be seen in Figure 3, with a solid line

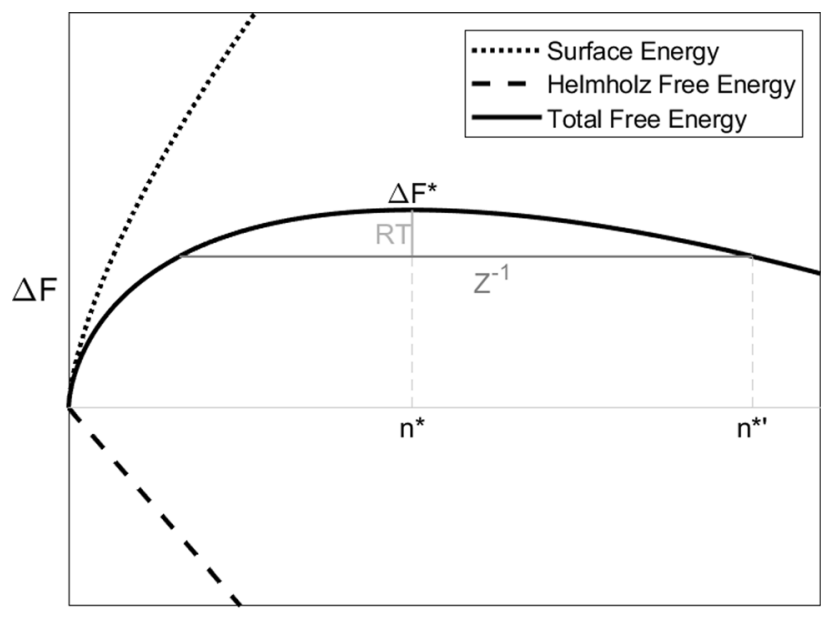

number of vacancies

Fig. 2- Graphical derivation of the Zeldovich factor. showing the grain boundary and a dashed line showing the grain boundary dissolved by the cavity.

The contact angle $\delta$ is given below in Eq. [6] by balancing the forces of the free surface energy, $\gamma_{\mathrm{m}}$, and the grain boundary energy, $\gamma_{g b}$.

$$
\delta=a \cos \left(\frac{\gamma_{\mathrm{gb}}}{2 \gamma_{\mathrm{m}}}\right)
$$

This so-called "wetting" effect reduces the volume and surface area of a cavity at the grain boundary, for a given fixed critical radius, and gives these cavities their characteristic lens shape. The cavities' size is also further reduced at triple boundary lines, where three grains meet and at quadruple grain boundary points, where four grains meet. The equations for volume and surface area were derived in previous works. ${ }^{[36,37]}$ As a result of the reduced volume the required free energy for nucleation of cavities lessens and so they form more readily. The three factors which favor heterogeneous over homogeneous nucleation are the accelerated diffusion along grain boundaries, the lower required free energy for nucleation and the abundant supply of vacancies. The lower number of nucleation sites, especially in the case of triple grain boundary lines and quadruple grain boundary points, compared to the bulk, reduce the nucleation at these sites.

The same "wetting" of cavities occurs on precipitates and inclusions, with the angle $\theta$, defined by the three interfacial energies between the cavity, the matrix, and the precipitate (Figure 4). This relation is shown in Eq. [7], where $\gamma_{\mathrm{m}}$ is the free surface energy of the matrix, $\gamma_{\mathrm{p}}$ is the free surface energy of the precipitate and $\gamma_{\mathrm{p}_{-} \mathrm{m}}$ is the interfacial energy between the matrix and the precipitate. The dissolution of the interface between the matrix and precipitate also lessens the critical free energy.

$$
\theta=a \cos \left(\frac{\gamma_{\mathrm{p} \_\mathrm{m}}-\gamma_{\mathrm{p}}}{\gamma_{\mathrm{m}}}\right)
$$

\section{Nucleation Rate for Grain Boundary Cavitation}

Inserting Eqs. [3] through [6] and the specific terms for the number of nucleation sites at the grain boundaries, $N_{\mathrm{GB}}$, the grain boundary diffusion coefficient, $D_{\mathrm{GB}}$, and the Arrhenius relationship for the equilibrium concentration of vacancies into Eq. [2], the nucleation rate at grain boundary surfaces becomes

$$
I=N_{\mathrm{GB}} \frac{A^{*}}{\sqrt[3]{\Omega^{4}}} \exp \left(\frac{-Q_{v}}{k T}\right) D_{\mathrm{GB}} \sqrt{\frac{\Delta F^{*}}{3 \pi R T}} \frac{1}{n^{*}} \exp \left(-\frac{\Delta F^{*}}{R T}\right)
$$

With the properties of the critical cavity; $V^{*}, n^{*}, A^{*}$ and $\Delta F^{*}$ representing the volume of the critical cavity, the number of vacancies in the critical cavity, the surface area of the critical cavity and the free energy needed to 


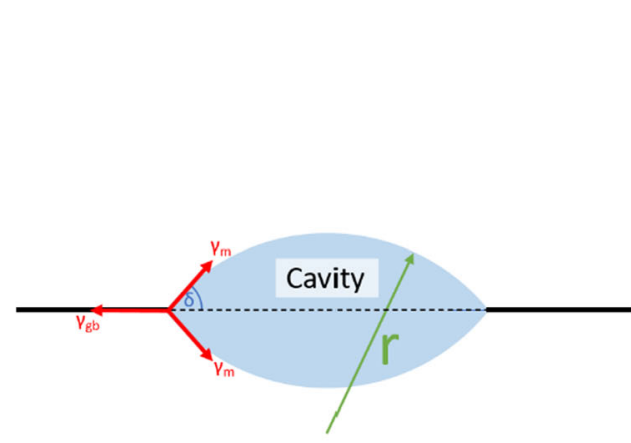

(a)

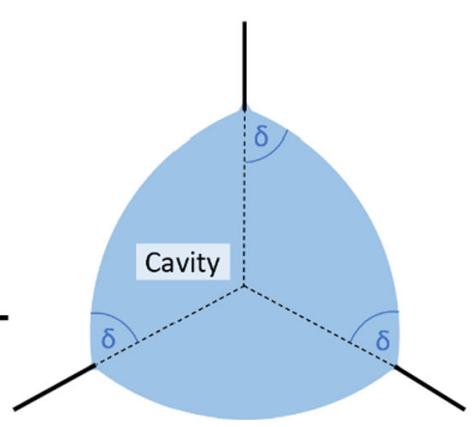

(b)

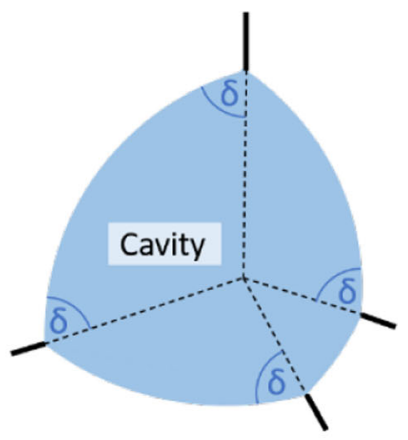

(c)

Fig. 3-Heterogeneous nucleation at (a) grain boundary surface, $(b)$ triple grain boundary line, $(c)$ quadruple grain boundary point.

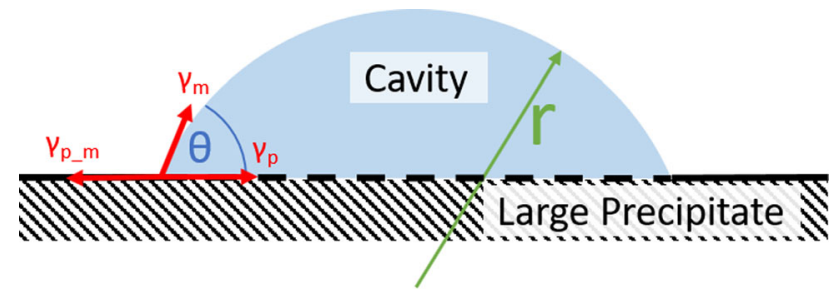

Fig. 4-Heterogeneous nucleation of a cavity on a large precipitate.

nucleate the critical cavity, respectively. The critical radius is calculated with Eq. [3].

$$
\begin{gathered}
V^{*}=\frac{4}{3} \pi r^{* 3}\left(\frac{(2+\cos (\delta)) \times(1-\cos (\delta))^{2}}{2}\right) \\
n^{*}=\frac{V^{*}}{\Omega} \\
A^{*}=4 \pi r^{* 2}(1-\cos (\delta)) \\
\Delta F^{*}=-\sigma V^{*}+\gamma_{\mathrm{m}} A^{*}+\gamma_{\mathrm{gb}} \pi r^{* 2}\left(\sin (\delta)^{2}\right)
\end{gathered}
$$

\section{E. Supercritical Cavity Growth}

In the previous section, the nucleation of cavities in the microstructure based on CNT was discussed. This model gives us steady state nucleation rates and number densities of cavities in the bulk, at the grain boundaries and on the surface of hard particles. However, the existing CNT model cannot predict the growth rate of cavities which have reached a critical size. We have modified the SFFK (Svoboda, Fischer, Fratzl, Kozeschnik) model ${ }^{[29]}$ for use in our simulations of cavity growth. The original equation for growth is,

$$
\dot{r}=\frac{\sigma-(2 \gamma / r)}{r R T} D_{0} u_{0} \Omega
$$

This equation arises from Onsager's principle of maximum entropy production ${ }^{[38]}$ which states that as a system reduces its total Gibbs' free energy on its way to thermodynamic equilibrium, the entropy increases at its maximum rate. Equation [13] is adapted as follows to generate Eq. [14] for the growth rate of the radius $\dot{r} . \sigma$ now represents the hydrostatic stress instead of the chemical driving force (analogous to our modifications to CNT), the diffusion coefficient $D_{0}$ is replaced with that for vacancy diffusion $D_{\mathrm{v}}$, the mean site fraction $u_{0}$ is replaced by the vacancy concentration $N_{\mathrm{V}}$ and the sintering stress term $(2 \gamma / r)$ now incorporates the free surface energy $\gamma_{\mathrm{m}} . \Omega$ is redefined from the molar volume to the atomic volume and correspondingly the Boltzmann constant $k_{\mathrm{b}}$ is used in place of the gas constant $R$.

$$
\dot{r}=\frac{\sigma-\left(2 \gamma_{\mathrm{m}} / r\right)}{r k_{\mathrm{b}} T} D_{\mathrm{V}} N_{\mathrm{V}} \Omega=\frac{D_{\mathrm{V}} N_{\mathrm{V}} \Omega}{k_{\mathrm{b}} T}\left(\frac{\sigma}{r}-\frac{2 \gamma_{\mathrm{m}}}{r^{2}}\right)
$$

The quotient of $\gamma_{\mathrm{m}}$ and $r$ describes the compression that the surface energy exerts on a curved surface which resists growth. Assuming a constant stress $\sigma$, a constant temperature $T$, a constant diffusion coefficient $D_{\mathrm{v}}$, and a constant supply of excess vacancies $N_{\mathrm{v}}$, the growth rate is completely deterministic and identical for all cavities. The more complex stress state at a strongly necked portion of a sample cannot currently be represented by this model.

\section{F. Kampmann-Wagner Framework}

To keep track of the nucleation and growth of all cavities in the microstructure we use a modified Kampmann-Wagner framework. ${ }^{[39]}$ During each timestep of the simulation, a new class of cavities is created with a population equal to the number of cavities nucleated in the last time interval. The starting radius of all cavities in this class is taken to be slightly overcritical (20 pct over $\left.r^{*}\right)$. For all subsequent timesteps, this radius evolves according to Eq. [14].

This framework provides a distribution of cavity sizes which is more useful and informative and can be compared to the histograms in Figure 5. 


\section{G. Simplifications in CNT Model}

Our implementation of CNT uses the capillarity approximation which means that nanoscale clusters are considered to have the same properties, such as free surface energy, as the bulk material at the macro scale. We also consider cavities to be spherical or lenticular. Future investigations into the lowest energy equilibrium shapes of cavities (Wulff shapes or similar) may decrease the required free energy to nucleate cavities.

Another valid point of criticism in CNT model is the application of global conditions, such as the stress on the entire sample, to the process of nucleation of nanosized particles (in our case, cavities). We have applied a correction to the stress, proposed by $\mathrm{Nix}^{[40]}$ to simplify the multiaxial stress acting on the grains to a single value that is used in our calculations.

Typically, literature values for the free surface energy are specified at room temperature, with a general decrease of surface energy at higher temperatures reported in Reference 41. Benson and Shuttleworth ${ }^{[42]}$ postulate that for the extreme case of a "droplet" consisting of a close-packed cluster of thirteen atoms, surface energies should only be reduced by about 15 pet. We are following the work of Sonderegger and Kozeschnik $^{[43]}$ using generalized nearest broken bond theory to calculate a theoretical surface energy according to Eq. [15].

$$
\gamma=\frac{n_{\mathrm{s}} z_{\mathrm{S}}}{N_{\mathrm{A}} z_{\mathrm{L}}} \Delta E_{\mathrm{sol}}
$$

This calculation uses $n_{s}$ as the number of atoms per unit of free surface area, the factor $z_{\mathrm{S}}$ as the number of bonds broken at the surface, $z_{L}$ as the total number of bonds and the energy of solution $\Delta E_{\mathrm{sol}}\left(=Q_{\mathrm{v}}\right.$ in our case). The calculated value of the free surface energy $\gamma_{\mathrm{m}}$ $=1.432 \mathrm{~J} \mathrm{~m}^{-1}$ is lower than other values found in literature. ${ }^{[41,44]}$

All simulations were run at constant temperature and stress for the duration of the creep time. The calculated nucleation rate is constant. This assumes that the number of possible nucleation sites does not decrease as new cavities are nucleated, which is reasonable at such low nucleation rates.

The mechanism of Ostwald ripening is not expected in this model because of the constant positive driving force, which predicts only the further growth of the stable cavities. Coalescence of cavities is also not considered since the cavity phase fraction is low for even the longest crept samples. This assumption is validated by the lack of coalescing cavities in the SEM images. This would only be needed to accurately model tertiary creep at the necked parts of samples which experience the most deformation.

\section{EXPERIMENTAL RESULTS}

\section{A. Density Measurements}

The density changes of the different samples after creep are shown in Figure 5 and summarized numerically in Table III. All samples (except S10) ruptured at approximately the same density of $7.79 \mathrm{~g} \mathrm{~cm}^{-3}$. This appears to be the threshold at which cavities are so numerous and large that they coalesce, and tertiary creep occurs, which quickly leads to failure. Sample S10, due to its high stress at $100 \mathrm{MPa}$, may have experienced more dislocation creep and therefore is presumed to have ruptured before cavitation could significantly reduce its density.

\section{B. Scanning Electron Microscopy}

The SEM was used to take 270 micrographs, of which 222 were evaluated, measuring 566 voids.

Figures 6(a) through (j) are representative micrographs of all samples, captured by SEM. Cavities at or near grain boundaries are highlighted in yellow and their radii are overlayed. The radii of all cavities measured vary from 10 to $110 \mathrm{~nm}$. The direction of applied stress is vertical in all micrographs.

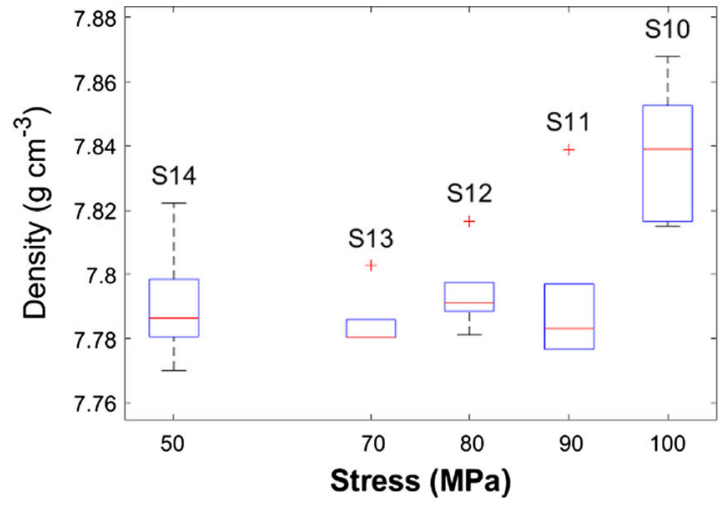

(a)

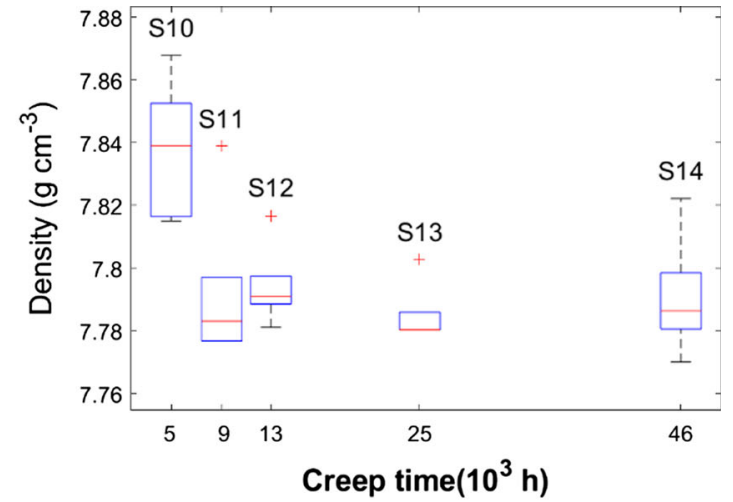

(b)

Fig. 5- Changes of density in different samples and different creep conditions based on $(a)$ applied stress and (b) time to rupture. 
Table III. Measured Densities of Sample Stubs

\begin{tabular}{lc}
\hline Sample & Density, Mean $\pm \mathrm{SD}\left(\mathrm{g} \mathrm{cm}^{-3}\right)$ \\
\hline S10 & $7.837 \pm 0.022$ \\
S11 & $7.792 \pm 0.027$ \\
S12 & $7.794 \pm 0.013$ \\
S13 & $7.785 \pm 0.010$ \\
S14 & $7.791 \pm 0.019$ \\
\hline
\end{tabular}

Cavities were identified as dark circles surrounded by bright annular rings, which shows the so-called "edge effect" due to the increased emission of secondary electrons on steep contours. ${ }^{[45]}$ The exclusive use of secondary electron imaging emphasizes the topological contrast in the micrographs. Spot checks with energy dispersive X-ray spectroscopy (EDX) revealed no significant changes in composition around the cavities.

Most cavities were observed at grain boundaries and this finding agrees well with the simulation results. We presume that the "wetting" effect (explained in Sect. III-C) lowered the free energy required for nucleation of those cavities. This and the fact that the failure mode during creep is predominantly intergranular fracture, ${ }^{[33]}$ caused by the growth and coalescence of cavities at the grain boundaries, led us to focus our investigations there. Cavities were found on grain boundaries in all orientations relative to the applied stress.

In Figures 6(f) and (j), some cavities can be seen near the precipitates, such as Laves-Phases, which appear bright in the SEM images because they mainly consist of heavy elements such as W and Mo. Nucleation at included particles and precipitates is also thermodynamically favorable, as explained by the model. However, due to their low number density, they do not nucleate enough cavities to contribute to the creep damage or affect the density, significantly.

The error in the cavity radii measurements caused by intersecting a roughly spherical cavity by an observation plane at an arbitrary height, was taken into account. We followed the approach proposed by Yadav et al.,${ }^{[46]}$ who found that, on average, the true radii, $r_{\mathrm{t}}$, can be estimated from the measured radii, $r_{\mathrm{m}}$, with Eq. [2].

$$
r_{\mathrm{t}}=\frac{4}{\pi} r_{\mathrm{m}}
$$

The limits of modern secondary electron microscopy (smallest detectable radii were approximately $10 \mathrm{~nm}$ ) and the influence of the polishing procedure also would influence the distribution of measured cavities' radii. The bright annular rings surrounding cavities, indicates that the edges of these cavities were not significantly rounded by the polishing. The interaction volume of the electron beam could also affect the measurements depending on the position of the intersecting plane relative to the center of the cavity. The distribution of measured radii appears nearly Gaussian which is in line with results from Jazeeri et al. ${ }^{[47]}$ who used small angle neutron scattering (SANS) to measure small cavities in crept samples.

Table IV shows the number of cavities measured per sample and the range of radii measured as well as the mean (average) radius of those cavities, all in nanometers.

Figure 7 shows the histogram of these measured cavities in $5 \mathrm{~nm}$ bins for each sample. Sample S10 covers the widest range with a few larger cavities between 70 and $80 \mathrm{~nm}$ in radius. This leads to it having the largest mean radius which is attributed to the high stress on this sample providing a stronger driving force for cavity growth. As stress decreased and creep rupture time increased, the radii of measured cavities increased slightly but steadily, as cavities are expected to grow during the creep tests. All histograms show a small number of cavities under $25 \mathrm{~nm}$ in radius. This is indicative of constant nucleation of small cavities until the end of the creep tests.

\section{Phase Fraction and Number Density}

Using the previous results from density measurements (Table III), the phase fraction of cavities is calculated, and shown in Table $\mathrm{V}$, assuming that the observed cavities are completely hollow and are the sole reason for the reduction in density. The base material's density was measured to be $8.02 \mathrm{~g} \mathrm{~cm}^{-3}$.

The mean volume per cavity, for each sample, is given in Eq. [17] as total volume of cavities (with true radius $\left.r_{\mathrm{t}, i}\right)$ measured, divided by the number of cavities, $n$.

$$
V_{\text {mean }}=\frac{1}{n} \sum_{i=1}^{n} \frac{4}{3} \pi r_{\mathrm{t}, i}^{3}
$$

The number density then represents the number of cavities of that specific mean volume required per cubic meter to occupy the calculated cavity fraction. This number density is shown in Table $\mathrm{V}$ and is plotted over creep time and creep stress in Figures 8(a) and (b) respectively. Samples S11 to S14 show similar number densities with a steady negative correlation with creep time and a positive correlation with creep stress. Sample S10 has the least cavities, due to its lower phase fraction and larger cavities which is again attributed to its high stress and accordingly, the different creep mechanism it experienced.

Figure 9 shows histograms of the quantified number density of radii of different sizes (in $5 \mathrm{~nm}$ bins) for each sample. As these results are obtained from the previous results of Table III and Figure 3 the histograms have a similar shape. Once again, a slight increase in cavity size as a function of creep time is observed as well as significantly fewer cavities in sample S10. 


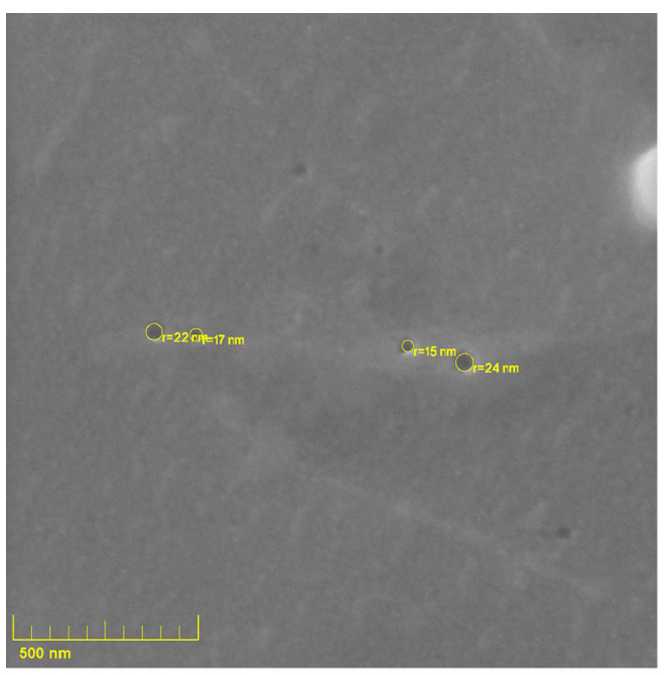

(a)

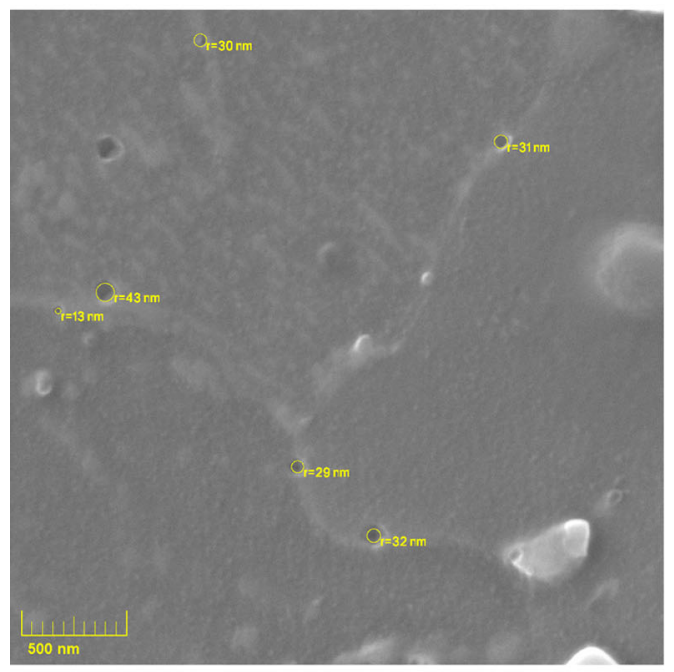

(c)

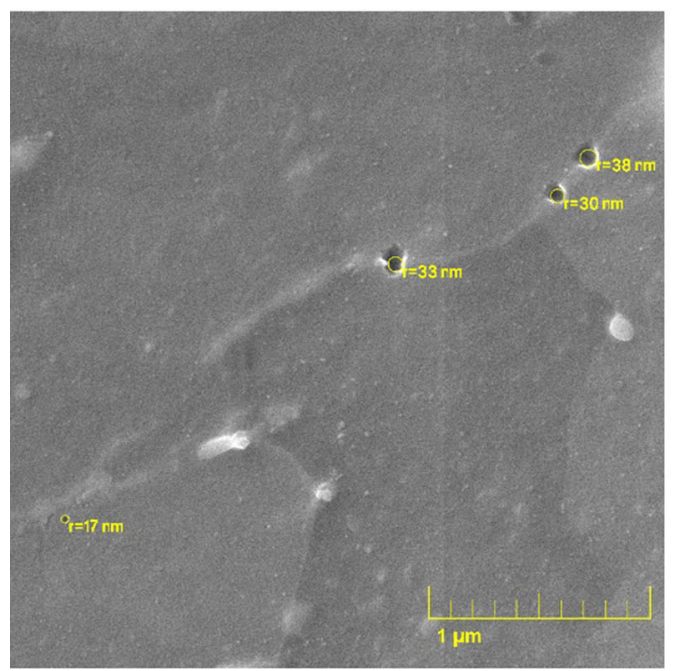

(e)

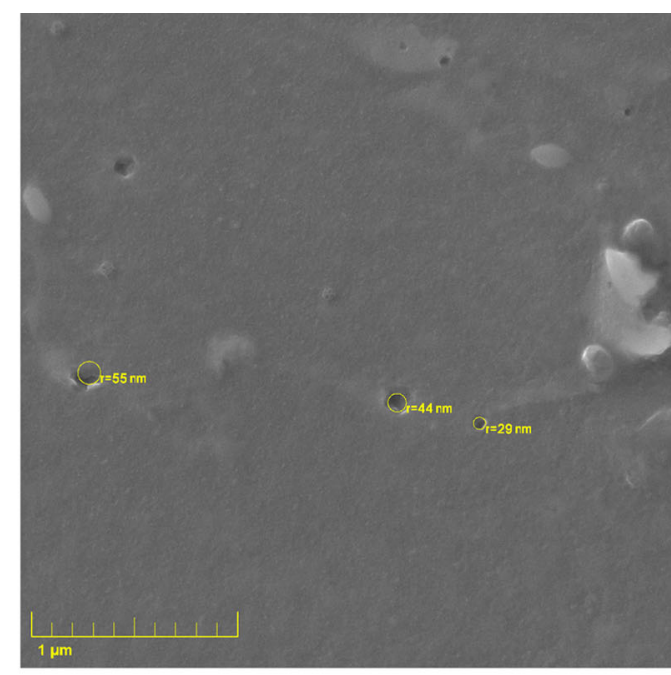

(b)

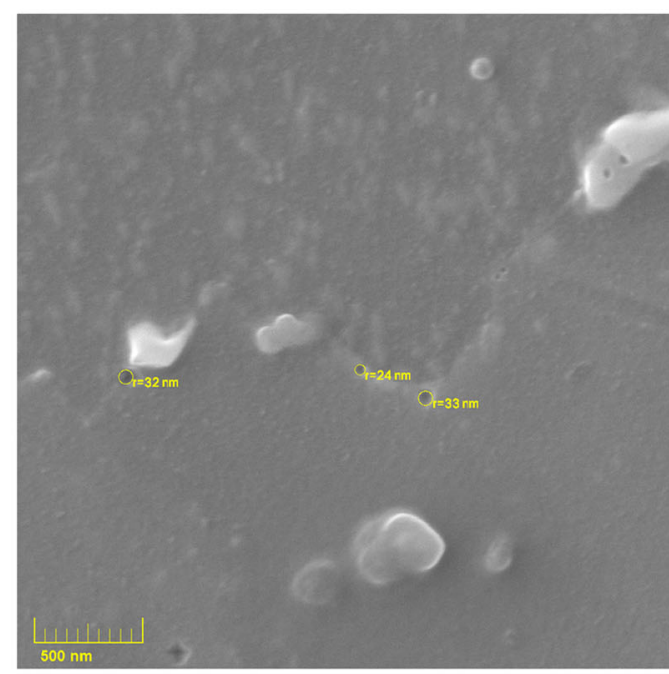

(d)

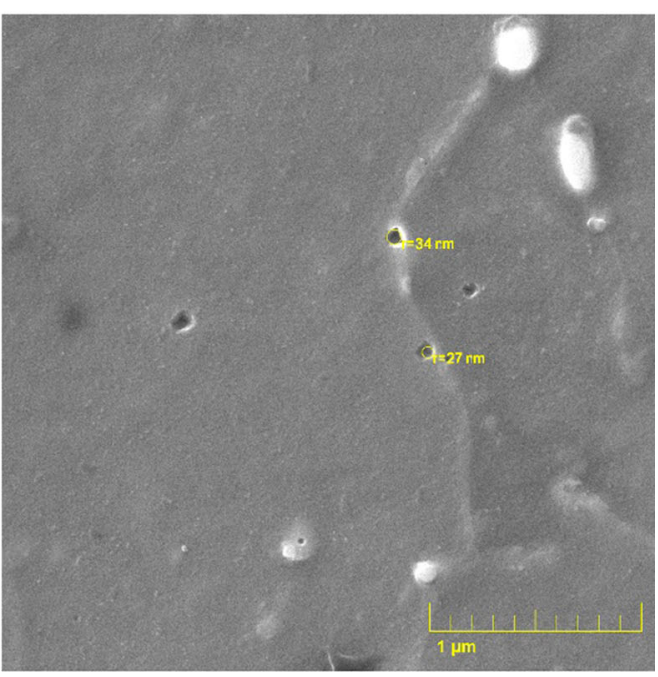

(f)

Fig. 6-SEM Images of highlighted cavities at grain boundaries in samples S10 $(a, b), \mathrm{S} 11(c, d), \mathrm{S} 12(e, f), \mathrm{S} 13(g, h)$ and $\mathrm{S} 14(i, j)$. 


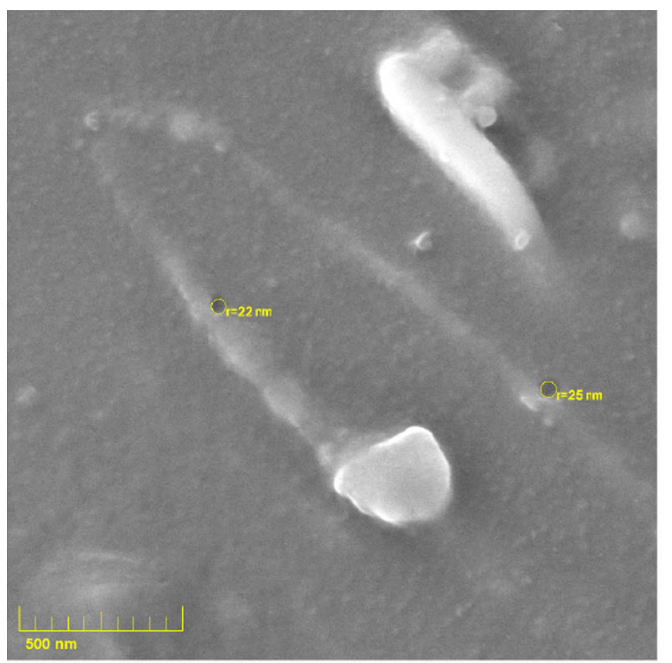

(g)

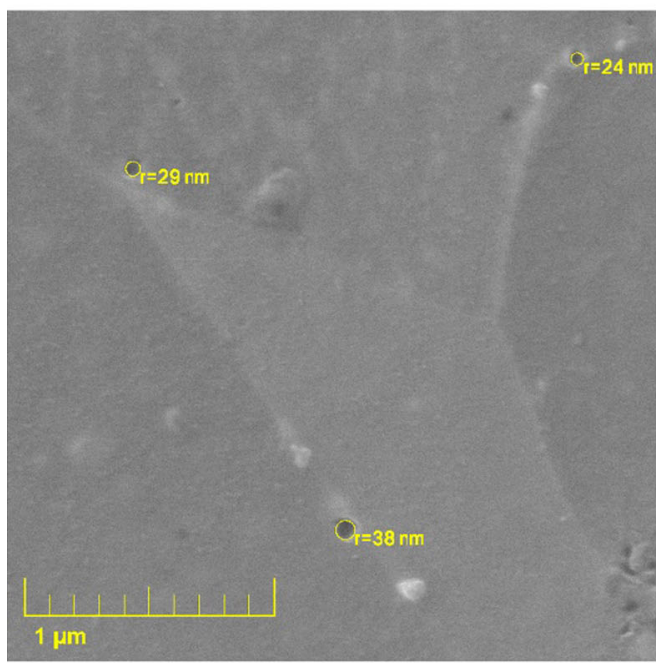

(i)

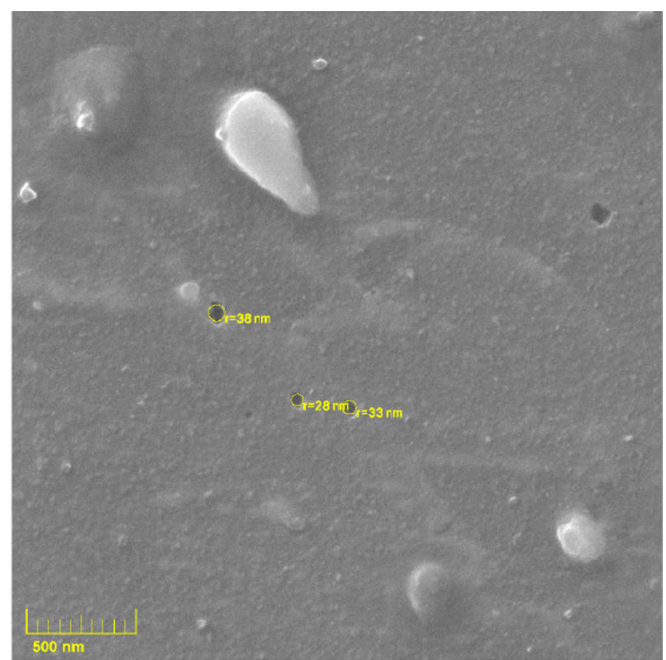

(h)

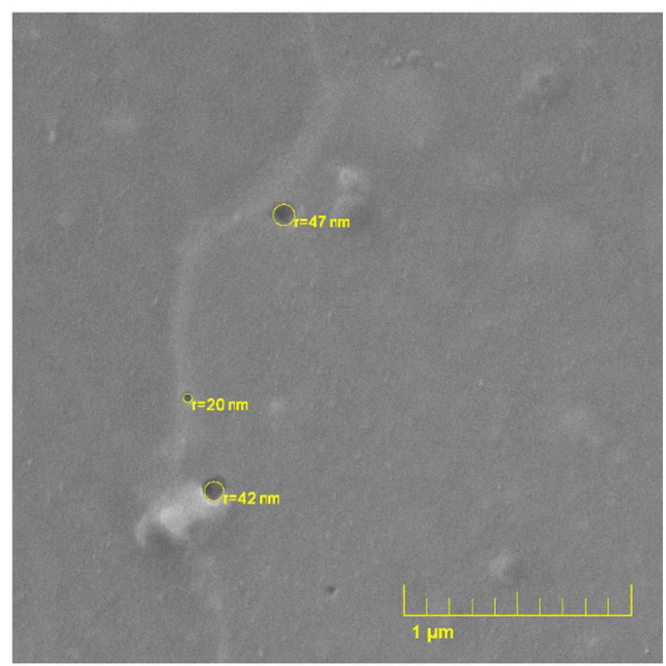

(j)

Fig. 6 - continued.

Table IV. Measured Cavity Radii in Samples After Creep Rupture

\begin{tabular}{lccc}
\hline Sample & Radius Range $(\mathrm{nm})$ & Mean Radius $(\mathrm{nm})$ & No. of Cavities Measured \\
\hline S10 & 18.1 to 112.3 & 52.2 & 107 \\
S11 & 16.3 to 67.4 & 39.7 & 92 \\
S12 & 14.4 to 74.7 & 39.9 & 71 \\
S13 & 15.2 to 73.7 & 41.1 & 147 \\
S14 & 15.0 to 91.5 & 45.4 & 149 \\
\hline
\end{tabular}

\section{SIMULATION RESULTS AND DISCUSSION}

To simulate the nucleation and growth of creep cavities, we applied the kinetic parameters and constants from Table VI. Most of these parameters were obtained directly from literature or were calculated with the help of formulas from literature. The mean grain diameter was measured from SEM images with the line intercept method. The width of the grain boundary was chosen to be similar to the lattice parameter, and matches other literature. ${ }^{[48,49]}$ Since this model is based almost entirely on physical and chemical properties it can be applied to other materials quite easily.

In this study we investigated the nucleation of creep cavities in the bulk, at grain boundaries and on hard particles. Table VII shows the simulation results of creep 


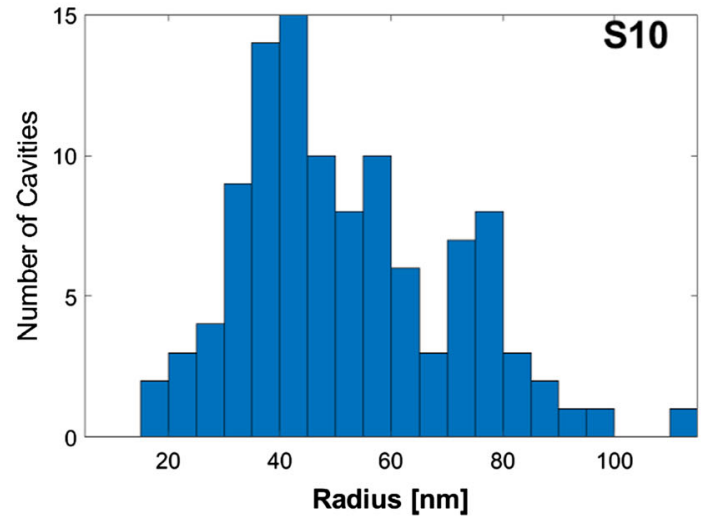

(a)

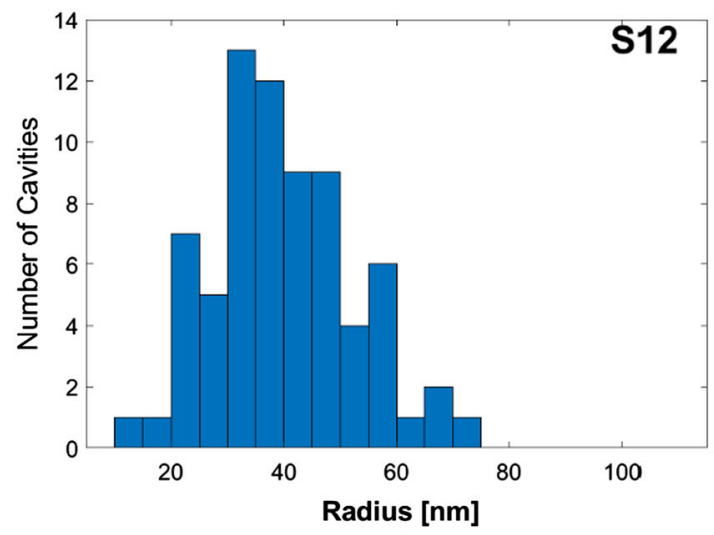

(c)

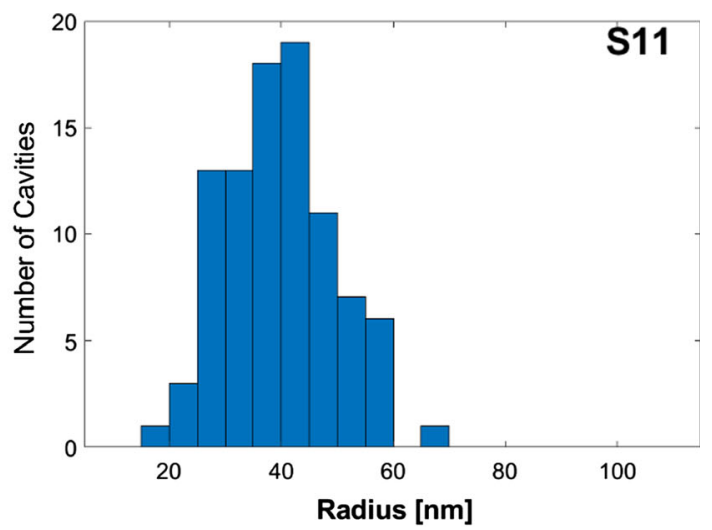

(b)

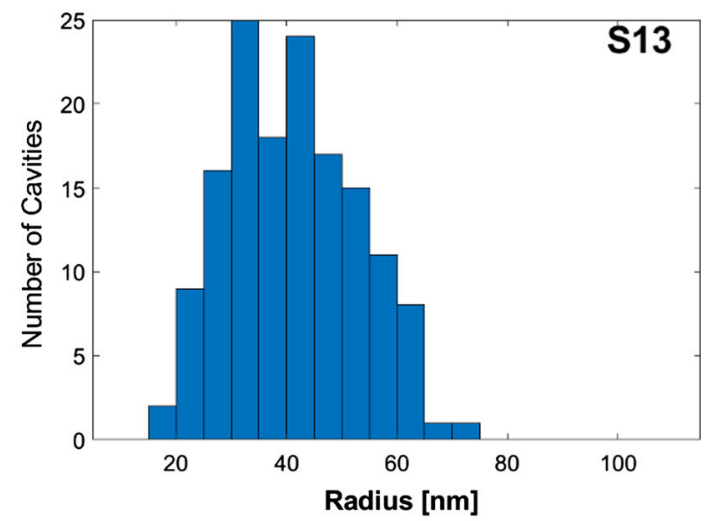

(d)

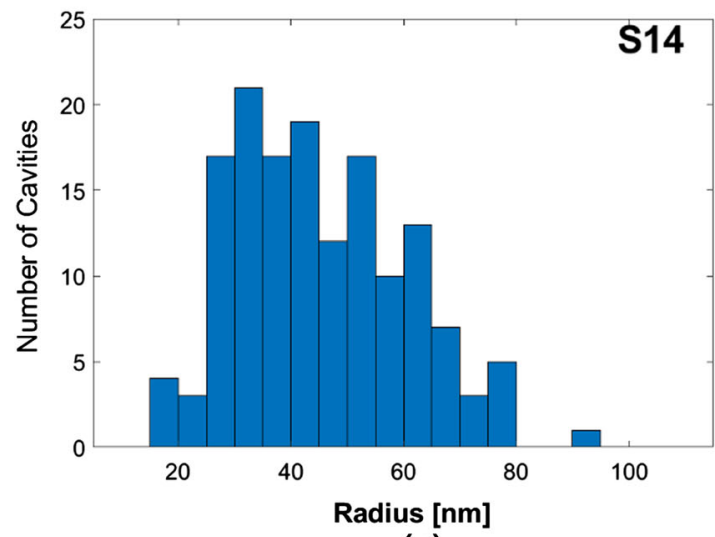

(e)

Fig. 7-Histograms of measured cavity radii in samples after creep rupture after (a) $4873 \mathrm{~h},($ b) 8995 h, (c) 12984 h, (d) $25093 \mathrm{~h},(e) 46321 \mathrm{~h}$

cavities in the bulk. As shown in Table VII, the phase fraction and ultimate radii of cavities is negligible. Consequently, these cavities did not contribute to the total cavitation in any meaningful way.

The number of nucleation sites at the precipitates was calculated by dividing the average precipitate surface area (from Matcalc calculations) by the square of the average interatomic distance, $a$, and then multiplying by the precipitate number density. This equates to the number of iron atoms at the surface of all precipitates of a given type per cubic meter. However, nucleation at these sites was ultimately negligible and therefore left out of the simulation results. 
Table V. Cavity Fraction and Number Density from Density Measurements and SEM Investigation

\begin{tabular}{lccc}
\hline Sample & $\mathrm{V}_{\text {mean }}\left(\mathrm{nm}^{3}\right)$ & Phase Fraction $($ Pct $)$ & ${\text { Number Density of Cavities }\left(\mathrm{m}^{-3}\right)}^{-3}$ \\
\hline S10 & 845419 & 2.28 & $2.70 \mathrm{E}+19$ \\
S11 & 333898 & 2.85 & $9.24 \mathrm{E}+19$ \\
S12 & 347183 & 2.82 & $8.10 \mathrm{E}+19$ \\
S13 & 365439 & 2.93 & $8.05 \mathrm{E}+19$ \\
S14 & 571480 & 2.86 & $5.41 \mathrm{E}+19$ \\
\hline
\end{tabular}

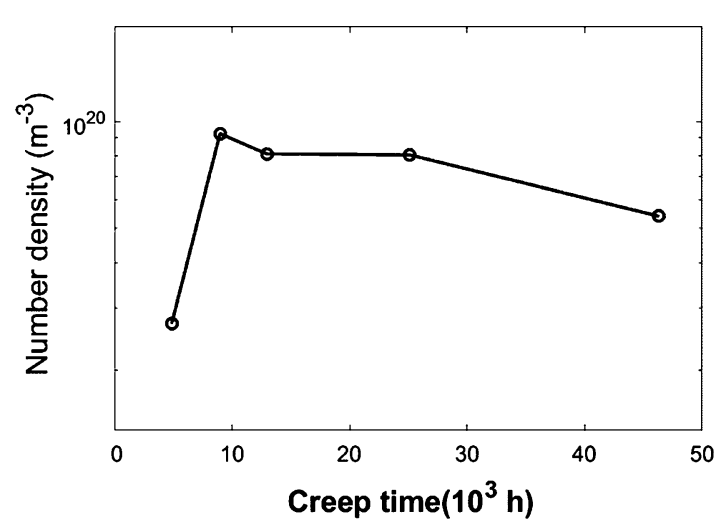

(a)

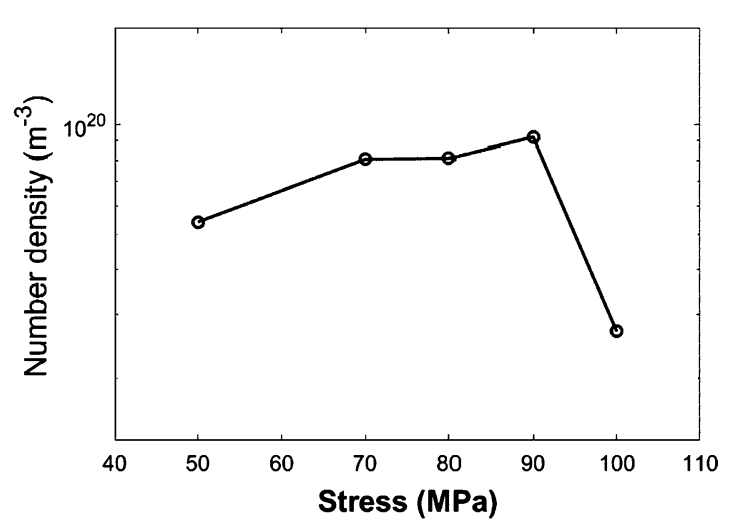

(b)

Fig. 8-Number density of cavities as a function of $(a)$ creep time to rupture and $(b)$ stress.

Table VIII shows the simulation results of nucleation rate, critical radius, and ultimate radius (of the largest cavities) in all samples. Although higher stresses reduce the critical radii and accelerate cavitation (according to Eq. [3]), the short failure times of the higher stressed samples led to smaller ultimate cavity sizes.

Table IX presents the extrapolated mean radii of cavities at the creep rupture times of the samples. The mean radii in this table increase with creep time, as also shown in the experimental results in Table IV, if we ignore the anomalous case of S10. This is reasonable and expected, however, there appears to be evidence of some process inhibiting growth or simultaneously shrinking the cavities.

Grain boundary triple lines and quadruple junctions, having 5 and 9 orders of magnitude fewer nucleation sites, respectively, did not nucleate sufficient cavities and were thus ruled out from further study. Their nucleation sites are also nearly impossible to detect and sufficiently sparse in two dimensional images to escape a quantifiable analysis.

Figure 10 shows how the results of simulation, in red, compare with the measured and quantified number density of cavities, in blue. The simulation of samples S12 and S13 agree well with the expected findings of cavity size and number density, although the shapes of the distributions differ somewhat. This could be due to various measurement and sampling errors during the
SEM investigation and the inhomogeneous growth conditions in the real microstructure when compared to the ideal circumstances of the simulation environment. The growth of cavities in Sample S11 is simulated more accurately although the nucleation rate is underestimated in the simulation. At the other extreme of our results, sample S14 shows less nucleation than its simulation. The lower phase fraction of cavities in this sample can be attributed to the self-healing of the microstructure by the alloying elements during this long creep time. This mechanism is found in steels containing Mo and $\mathrm{W}$. ${ }^{[54,55]}$

Figure 11 shows the growth curves of cavities which are nucleated at the beginning of the various creep experiments and grow during their entire duration. Samples under the highest stress start out with the smallest critical cavities (see Eq. [3]), however they also experience a stronger driving force and faster growth, as seen by the steep gradient of the curves. The growth rate (first derivative of the cavity radius with respect to time) reaches its maximum at precisely twice the critical radius.

Although the model would correctly predict the shrinking of cavities and lack of nucleation under compressive stress, all grain boundaries were assumed to be under tension in agreement with the experimental results described in Figure 6, wherein cavities are found at grain boundaries at all angles relative to creep load. 


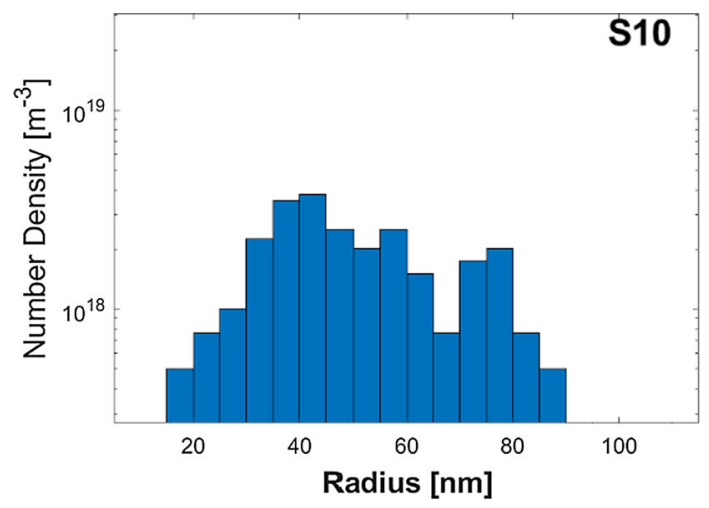

(a)

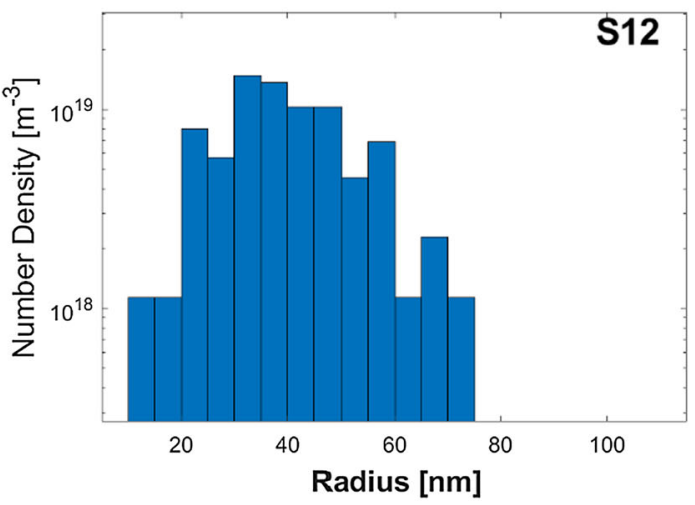

(c)

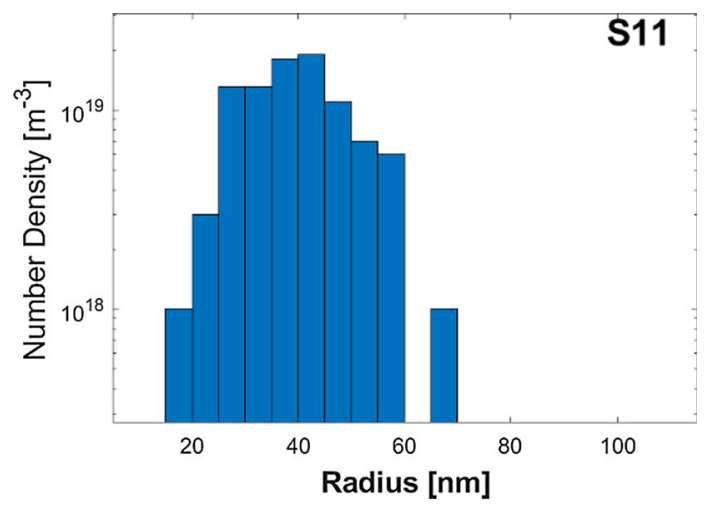

(b)

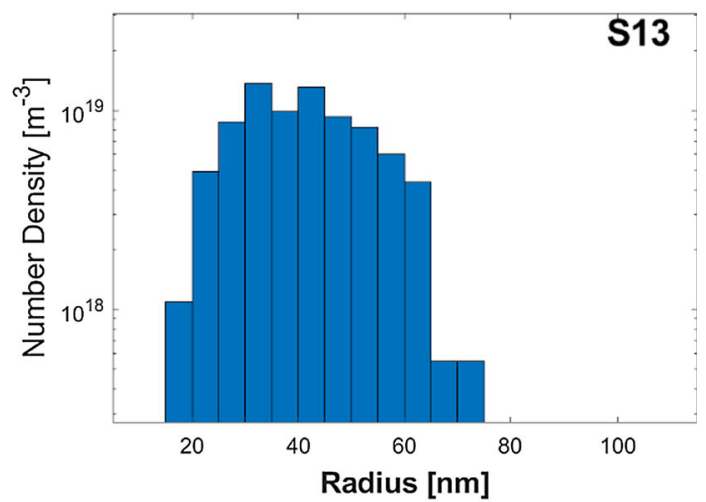

(d)

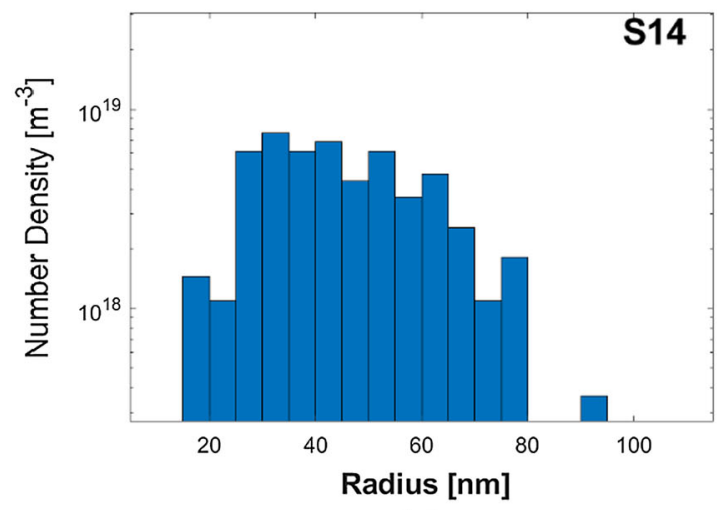

(e)

Fig. 9-Measured cavity radii and quantified number density at (a) $100 \mathrm{MPa}, 4873 \mathrm{~h}$; (b) $90 \mathrm{MPa}, 8995 \mathrm{~h} ;($ c) $80 \mathrm{MPa}, 12984 \mathrm{~h}$; (d) $70 \mathrm{MPa}$, $25093 \mathrm{~h}$; (e) $50 \mathrm{MPa}, 46,321 \mathrm{~h}$ creep conditions.

Critical cavity sizes, critical energies and thus nucleation rates are dependent on grain boundary energy (see Eqs. [6], [9] and [12]), which is reported to vary with grain misorientation and grain boundary orientation. ${ }^{[50,56]}$ Future investigations together with electron backscatter diffraction (EBSD) measurements may provide better insight into the effect of these variations. In this work, an approximately median value from literature was taken to represent all grain boundaries, although this is would depend on the distribution of grain boundary orientations and misorientations in the real material. 
Table VI. Model Parameters and Constants Used for Simulation of Creep Cavities in This Study

\begin{tabular}{|c|c|c|}
\hline Parameter & Description & Value \\
\hline $\begin{array}{l}\gamma_{m} \\
\gamma_{g b} \\
\gamma_{l} \\
\gamma_{l-m} \\
\gamma_{c} \\
\gamma_{c \_} m \\
Q_{v} \\
l_{p} \\
\Omega \\
\delta_{g} \\
v \\
T \\
\sigma \\
D_{B} \\
D_{G B} \\
D_{D} \\
R \\
k \\
N_{A} \\
a \\
N_{B} \\
N_{G B} \\
N_{G B 3} \\
N_{G B} \\
d_{g} \\
z_{S} / z_{l}\end{array}$ & $\begin{array}{l}\text { free surface energy of iron } \\
\text { grain boundary energy of iron } \\
\text { free surface energy of laves phase } \\
\text { interfacial energy of laves phase } \\
\text { free surface energy of } \mathrm{M}_{23} \mathrm{C}_{6} \\
\text { interfacial energy of } \mathrm{M}_{23} \mathrm{C}_{6} \\
\text { vacancy formation energy } \\
\text { lattice parameter of bcc iron } \\
\text { atomic volume } \\
\text { width of grain boundary } \\
\text { atomic vibration frequency } \\
\text { temperature } \\
\text { stress on sample } \\
\text { bulk diffusion coefficient } \\
\text { diffusion coefficient along grain boundaries } \\
\text { diffusion coefficient along dislocations } \\
\text { molar gas constant } \\
\text { Boltzmann constant } \\
\text { Avogadro constant } \\
\text { interatomic spacing }\left(\Omega^{1 / 3}\right) \\
\text { number of nucleation sites in bulk }\left(\Omega^{-1}\right) \\
\text { number of nucleation sites at grain boundaries } \\
\text { number of nucleation sites at grain edges } \\
\text { number of nucleation sites at grain corners } \\
\text { mean grain diameter } \\
\text { ratio of bonds broken to total bonds in BCC }\end{array}$ & $\begin{array}{l}1.432 \mathrm{~J} \mathrm{~m}^{-1}(\text { Eq. [15]) } \\
0.75 \mathrm{~J} \mathrm{~m}^{-1[50]} \\
0.099 \mathrm{~J} \mathrm{~m}^{-1[12]} \\
0.31 \mathrm{~J} \mathrm{~m}^{-1[12]} \\
0.021 \mathrm{~J} \mathrm{~m}^{-1[12]} \\
0.41 \mathrm{~J} \mathrm{~m}^{-1[12]} \\
1.4 \mathrm{eV}^{[51]} \\
0.2866 \mathrm{~nm}^{[52]} \\
1.1771 \times 10^{-29} \mathrm{~m} \\
0.5 \mathrm{~nm} \\
20.8 \times 10^{10} \mathrm{~s}^{-1} \mathrm{~K}^{-1} \mathrm{~T}^{-1[12]} \\
873 \mathrm{~K}\left(600{ }^{\circ} \mathrm{C}\right) \\
50,70,80,90,100 \mathrm{MPa}^{10}, \\
2.7 \times 10^{-20} \mathrm{~m}^{2} \mathrm{~s}^{-1[28]} \\
1.01 \times 10^{-13} \mathrm{~m}^{2} \mathrm{~s}^{-1[28]} \\
8.17 \times 10^{-15} \mathrm{~m}^{2} \mathrm{~s}^{-1[28]} \\
8.3145 \mathrm{~J} \mathrm{~mol}^{-1} \mathrm{~K}^{-1} \\
1.380649 \times 10^{-23} \mathrm{~J} \mathrm{~K}^{-1} \\
6.02214076 \times 10^{23} \mathrm{~mol}^{-1} \\
0.2747 \mathrm{~nm}^{28} \mathrm{~m}^{-3} \\
8.5 \times 10^{25} \mathrm{~m}^{-3[53]} \\
\left.1.5 \times 10^{25} \mathrm{~m}^{-3} \times 153\right] \\
2.7 \times 10^{21} \mathrm{~m}^{-3[53} \\
4.7 \times 10^{17} \mathrm{~m}^{-3[53]} \\
2.8 \mu \mathrm{m}^{[43]} \\
0.328^{[43]}\end{array}$ \\
\hline
\end{tabular}

Table VII. Simulation Results of Creep Cavities in the Bulk

\begin{tabular}{lcccc}
\hline Sample & Stress $(\mathrm{MPa})$ & Critical Radius $(\mathrm{nm})$ & Ultimate Radius $(\mathrm{nm})$ & Final Phase Fraction \\
\hline S10 & 100 & 12.8 & 13.4 & $3.67 \mathrm{E}-7$ \\
S11 & 90 & 14.2 & 14.9 & $9.28 \mathrm{E}-7$ \\
S12 & 80 & 16.0 & 16.8 & $1.91 \mathrm{E}-6$ \\
S13 & 70 & 18.3 & 19.2 & $5.50 \mathrm{E}-6$ \\
S14 & 50 & 25.6 & 26.8 & $2.79 \mathrm{E}-5$ \\
\hline
\end{tabular}

Table VIII. Simulation Results of Nucleation and Growth of Creep Cavities at Grain Boundaries

\begin{tabular}{lcccc}
\hline Sample & Stress $(\mathrm{MPa})$ & Nucleation Rate $\left(\mathrm{m}^{-3} \mathrm{~s}^{-1}\right)$ & Critical Radius (nm) & Ultimate Radius (nm) \\
\hline S10 & 100 & $7.91 \mathrm{E}+11$ & 12.8 & 41.3 \\
S11 & 90 & $7.91 \mathrm{E}+11$ & 14.2 & 56.4 \\
S12 & $8.91 \mathrm{E}+11$ & 16.0 & 64.0 \\
S13 & 70 & $7.91 \mathrm{E}+11$ & 25.3 & 87.0 \\
S14 & 50 & $7.91 \mathrm{E}+11$ & 25.6 & 93.2 \\
\hline
\end{tabular}

\section{CONCLUSION}

In this study, a new physically based model was presented for the nucleation and growth of creep cavities in crystalline materials. The suggested model was applied to simulate creep cavitation of the bainitic steel p23 after creep times of up to 46000 hours. The integration of a Kampmann-Wagner model to account for multiple size classes of cavities demonstrates that the proposed model can also describe the growth evolution of all cavities individually.

The microstructural analysis and simulation agree well in certain aspects. The calculated critical radii, i.e., the starting point of growth of newly nucleated cavities, are similar in size to the smallest cavities observed along 
Table IX. Evolution of Mean Radii of Grain Boundary Cavities

\begin{tabular}{lllccc}
\hline & \multicolumn{3}{c}{ Mean Radius (nm) After Time (h) } \\
Sample & 4873 & 8995 & 12,984 & 25,093 & 46,321 \\
\hline S10 & $25.8^{*}$ & 38.0 & 48.2 & 72.8 & 105 \\
S11 & 24.0 & $34.5^{*}$ & 43.7 & 66.5 & 96.8 \\
S12 & 22.8 & 31.2 & $39.1^{*}$ & 59.8 & 87.9 \\
S13 & 22.8 & 28.7 & 35.0 & $52.8^{*}$ & 78.3 \\
S14 & 28.0 & 29.6 & 31.7 & 40.5 & $57.4^{*}$ \\
\hline \multicolumn{2}{r}{ *Size of creep cavities at rupture time. }
\end{tabular}

*Size of creep cavities at rupture time.

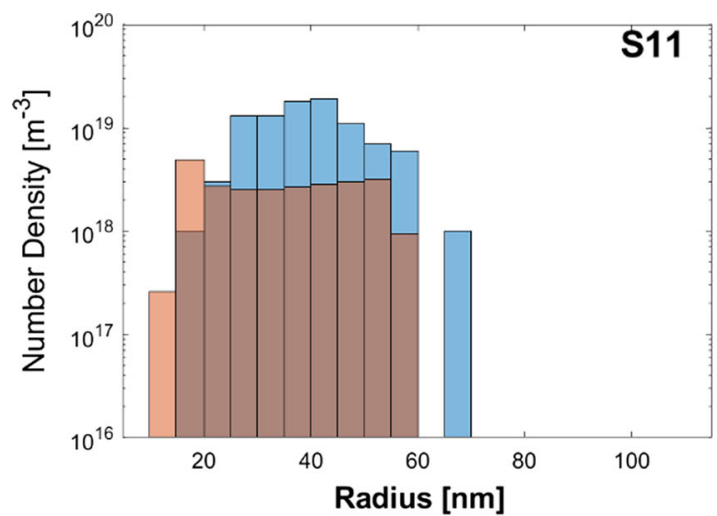

(a)

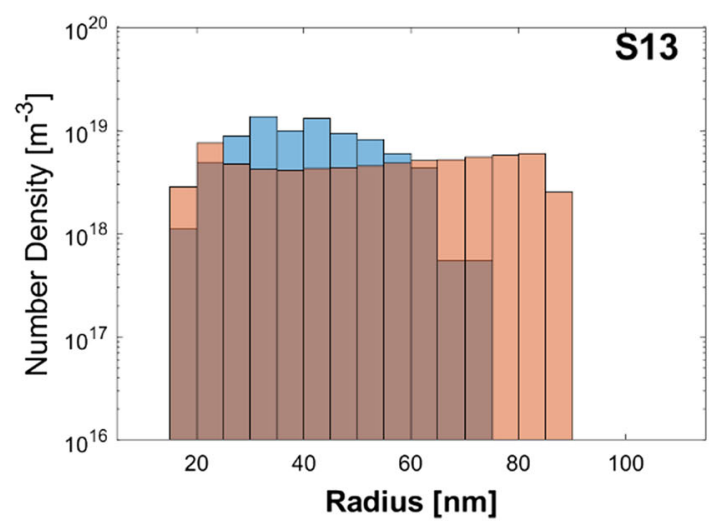

(c)

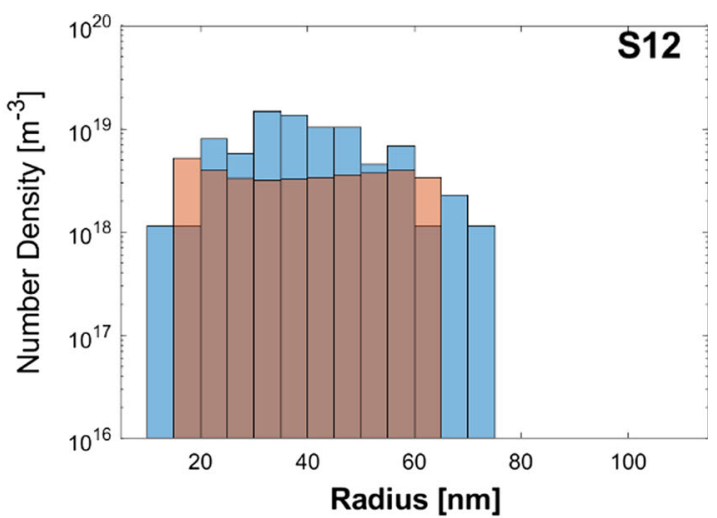

(b)

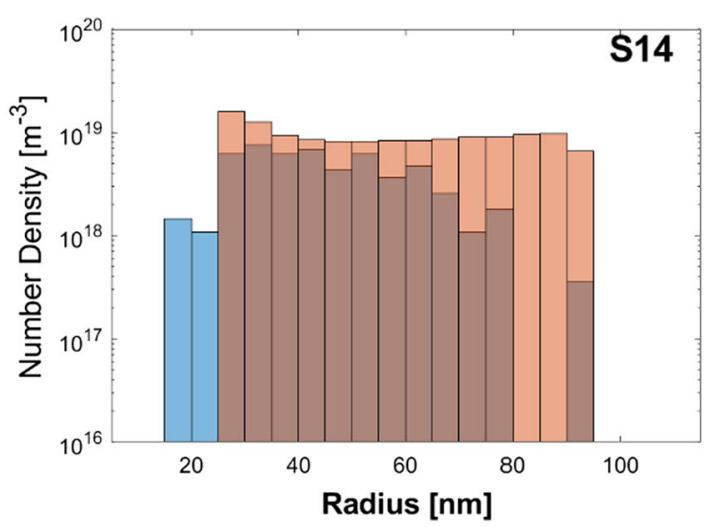

(d)

Fig. 10-Histograms comparing quantified (blue) and calculated (red) number densities for cavities (in $5 \mathrm{~nm}$ bins) at (a) $90 \mathrm{MPa}, 8995 \mathrm{~h}$; (b) 80 MPa, 12984 h; (c) $70 \mathrm{MPa}, 25,093 \mathrm{~h}$; (d) $50 \mathrm{MPa}, 46,321 \mathrm{~h}$ creep conditions (Color figure online).

the grain boundaries. Both the SEM images and the proposed model agree that cavitation is much more frequent at grain boundaries than at other sites in the microstructure.

The qualitative prediction of cavity nucleation rates agrees well for all samples (at lower stresses) that seem to principally experience diffusion-controlled cavity nucleation. The transition from diffusion-controlled to dislocation-controlled creep explains the greater deviation between experimental and simulated results in sample S10, although it was expected to be more gradual than this investigation would suggest. The slight deviation between the proposed model's and the observed results on samples undergoing long creep times may be attributed to the self-healing of cavities by alloying elements. ${ }^{[57]}$ 


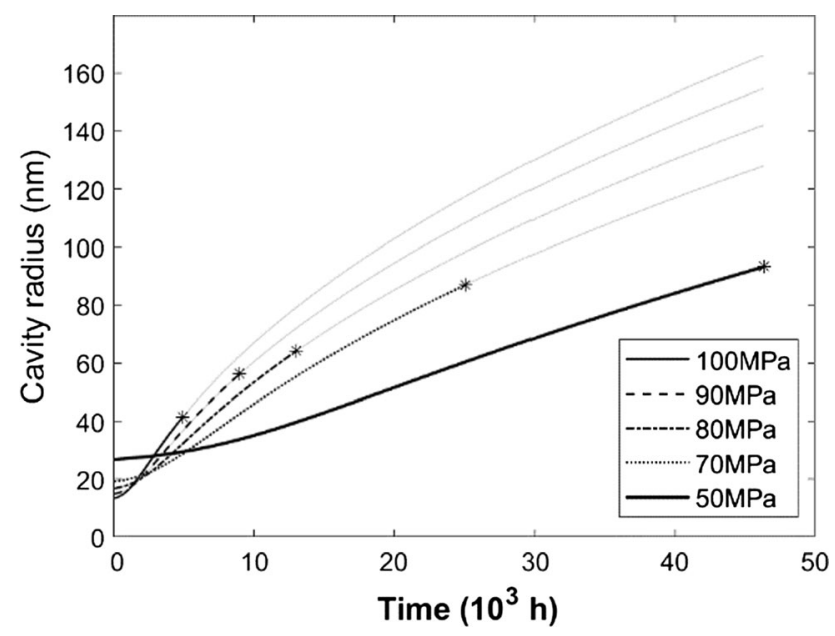

Fig. 11-Simulation results of cavity growth under different creep stresses. The $*$ signifies the ultimate radius at rupture and the thin gray lines represent theoretical growth beyond rupture.

\section{ACKNOWLEDGMENTS}

This research was funded by the TU Graz Lead Project "Porous Materials at Work" (LP-03). We would like to thank Roland Würschum and his team at the Institute of Materials Physics of Graz University of Technology for the opportunity to perform investigations there. We also thank Bernhard Sonderegger and Ernst Kozeschnik for prompt answers to all questions. This work was also supported by our colleagues Fernando Warchomicka and Florian Riedlsperger.

\section{DATA AVAILABILITY}

The raw/processed data required to reproduce these findings cannot be shared at this time due to technical or time limitations.

\section{CONFLICT OF INTEREST}

On behalf of all authors, the corresponding author states that there is no conflict of interest.

\section{FUNDING}

Open access funding provided by Graz University of Technology.

\section{OPEN ACCESS}

This article is licensed under a Creative Commons Attribution 4.0 International License, which permits use, sharing, adaptation, distribution and reproduction in any medium or format, as long as you give appropriate credit to the original author(s) and the source, provide a link to the Creative Commons licence, and indicate if changes were made. The images or other third party material in this article are included in the article's Creative Commons licence, unless indicated otherwise in a credit line to the material. If material is not included in the article's Creative Commons licence and your intended use is not permitted by statutory regulation or exceeds the permitted use, you will need to obtain permission directly from the copyright holder. To view a copy of this licence, visit http://creat ivecommons.org/licenses/by/4.0/.

\section{REFERENCES}

1. R. Viswanathan and W. Bakker: J. Mater. Eng. Perform., 2001, vol. 10, pp. 81-95.

2. J.A. Jiménez, M. Carsí, and O.A. Ruano: J. Mater. Sci. Technol., 2017, vol. 33, pp. 1487-93.

3. P. von Hartrott, S. Holmström, S. Caminada, and S. Pillot: Mater. Sci. Eng. A., 2009, vol. 510-511, pp. 175-9.

4. M.F. Ashby: Advances in Applied Mechanics, vol. 23, Academic Press, New York, 1983, pp. 117-77.

5. J. Hald: Trans. Indian Inst. Met., 2016, vol. 69, pp. 183-8.

6. A.J. Perry: J. Mater. Sci., 1974, vol. 9, pp. 1016-39.

7. M.E. Kassner and T.A. Hayes: Int. J. Plasticity., 2003, vol. 19, pp. $1715-48$.

8. M.E. Kassner and M.T. Pérez-Prado: Fundamentals of Creep in Metals and Alloys, Elsevier, 2015.

9. J. He and R. Sandström: Theor. Appl. Fract. Mech., 2017, vol. 89, pp. 139-46.

10. B.F. Dyson: Scr. Metall., 1983, vol. 17, pp. 31-7.

11. L. Huang, M. Sauzay, Y. Cui, and P. Bonnaille: Mater. Sci. Eng. $A, 2021$, vol. 813, p. 140953 .

12. M.R. Ahmadi, B. Sonderegger, S.D. Yadav, and C. Poletti: Mater. Sci. Eng. A., 2018, vol. 712, pp. 466-77.

13. R. Raj and M.F. Ashby: Acta Metall., 1975, vol. 23, pp. 653-66.

14. D.L.C. Neves, J.R. de C. Seixas, E.B. Tinoco, A. da C. Rocha, and I. de C. Abud: Mater. Res., 2004, vol. 7, pp. 155-61.

15. A.C.F. Cocks and M.F. Ashby: Met. Sci., 1980, vol. 14, pp. 395-402.

16. W. Bendick, J. Gabrel, B. Hahn, and B. Vandenberghe: Int. J. Press. Vessel. Pip., 2007, vol. 84, pp. 13-20.

17. J.A. Siefert and J.D. Parker: Int. J. Press. Vessel. Pip., 2016, vol. 138, pp. 31-44.

18. J.C. Vaillant, B. Vandenberghe, B. Hahn, H. Heuser, and C. Jochum: Int. J. Press. Vessel. Pip., 2008, vol. 85, pp. 38-46.

19. P. Mayr: Diploma Thesis, Graz University of Technology, 2003.

20. M. Sroka and A. Zieliński: Arch. Mater. Sci. Eng., 2013, vol. 64, pp. 205-12.

21. M. Volmer and $\alpha$ Weber: Z. Phys. Chem., 1926, vol. 119U, pp. 277-301.

22. R. Becker and W. Doring: Ann. Phys., 1935, vol. 416, pp. 719-52.

23. J. Frenkel: J. Chem. Phys., 1939, vol. 7, pp. 538-47.

24. Y.B. Zeldovich and R. Sunyaev: in Selected Works of Yakov Borisovich Zeldovich, Volume I, Princeton University Press, Princeton, 1992, pp. 120-37.

25. D.W. Oxtoby: J. Phys. Condens. Matter., 1992, vol. 4, pp. 7627-50.

26. V.V. Slezov and J. Schmelzer: J. Phys. Chem. Solids., 1994, vol. 55, pp. 243-51.

27. J. Feder, K.C. Russell, J. Lothe, and G.M. Pound: Adv. Phys., 1966, vol. 15, pp. 111-78.

28. E. Kozeschnik: Modeling Solid-State Precipitation, Momentum Press, New York, 2012.

29. J. Svoboda, F.D. Fischer, P. Fratzl, and E. Kozeschnik: Mater. Sci. Eng. A., 2004, vol. 385, pp. 166-74.

30. E. Kozeschinik: Matcalc, www.matcalc.at.

31. B.M. Clemens, W.D. Nix, and R.J. Gleixner: J. Mater. Res., 1997, vol. 12 , pp. 2038-42.

32. R.J. Gleixner, B.M. Clemens, and W.D. Nix: J. Mater. Res., 1997, vol. 12 , pp. 2081-90.

33. H. Riedel: Fracture at High Temperatures, Springer, Berlin, 1987.

34. J. Cadek: Creep in Metallic Materials, Elsevier, Amsterdam, 1988.

35. J.P. Hirth and W.D. Nix: Acta Metall., 1985, vol. 33, pp. 359-68.

36. J.K. Lee and H. Aaronson: Acta Metall., 1975, vol. 23, pp. 809-20. 
37. P.J. Clemm and J.C. Fisher: Acta Metall., 1955, vol. 3, pp. 70-3.

38. L. Onsager: Phys. Rev., 1931, vol. 37, pp. 405-26.

39. R. Wagner, R. Kampmann, and P.W. Voorhees: in Phase Transformations in Metals, Wiley-VCH Verlag GmbH \& Co. KGaA, Weinheim, Germany, 2013, pp. 309-407.

40. W.D. Nix, J.C. Earthman, G. Eggeler, and B. Ilschner: Acta Metall., 1989, vol. 37, pp. 1067-77.

41. S. Schönecker, X. Li, B. Johansson, S.K. Kwon, and L. Vitos: Sci. Rep., 2015, vol. 5, pp. 1-7.

42. G.C. Benson and R. Shuttleworth: J. Chem. Phys., 1951, vol. 19, pp. $130-1$.

43. B. Sonderegger and E. Kozeschnik: Metall. Mater. Trans. A Phys. Metall. Mater. Sci., 2009, vol. 40, pp. 499-510.

44. T.A. Roth: Mater. Sci. Eng., 1975, vol. 18, pp. 183-92.

45. M.I. Szynkowska: in Encyclopedia of Analytical Science, Elsevier, 2005, pp. $134-43$.

46. S.D. Yadav, B. Sonderegger, B. Sartory, C. Sommitsch, and C. Poletti: Mater. Sci. Technol. (U. K.)., 2015, vol. 31, pp. 554-64.

47. H. Jazaeri, P.J. Bouchard, M.T. Hutchings, M.W. Spindler, A.A. Mamun, and R.K. Heenan: Metals (Basel), https://doi.org/10.33 90/met9030318.

48. A. Inoue, H. Nitta, and Y. Iijima: Acta Mater., 2007, vol. 55, pp. 5910-6.

49. D. Prokoshkina, V.A. Esin, G. Wilde, and S.V. Divinski: Acta Mater., 2013, vol. 61, pp. 5188-97.
50. H. Beladi and G.S. Rohrer: Acta Mater., 2013, vol. 61, pp. $1404-12$.

51. S.M. Kim and W.J.L. Buyers: J. Phys. F Met. Phys., 1978, vol. 8, pp. 103-8.

52. J.W. Arblaster: Selected Values of the Crystallographic Properties of Elements, ASM International, Materials Park, 2018.

53. R.D. Doherty: Physical Metallurgy, Elsevier, Amsterdam, 1996, p. 2740 .

54. S. Zhang, H. Fang, M.E. Gramsma, C. Kwakernaak, W.G. Sloof, F.D. Tichelaar, M. Kuzmina, M. Herbig, D. Raabe, E. Brück, S. van der Zwaag, and N.H. van Dijk: Metall. Mater. Trans. A Phys. Metall. Mater. Sci., 2016, vol. 47, pp. 4831-44.

55. H. Fang, N. Szymanski, C.D. Versteylen, P. Cloetens, C. Kwakernaak, W.G. Sloof, F.D. Tichelaar, S. Balachandran, M. Herbig, E. Brück, S. van der Zwaag, and N.H. van Dijk: Acta Mater., 2019, vol. 166, pp. 531-42.

56. O. Kapikranian, H. Zapolsky, C. Domain, R. Patte, C. Pareige, B. Radiguet, and P. Pareige: Phys. Rev. B Condens. Matter Mater. Phys., 2014, vol. 89, pp. 1-8.

57. C.D. Versteylen, M.H.F. Sluiter, and N.H. van Dijk: J. Mater. Sci., 2018, vol. 53, pp. 14758-73.

Publisher's Note Springer Nature remains neutral with regard to jurisdictional claims in published maps and institutional affiliations. 